\title{
PUBLIC DEVELOPMENT BANKS AND CREDIT MARKET IMPERFECTIONS
}

\author{
Marcela Eslava \\ Xavier Freixas
}

\section{LATIN AMERICAN AND THE CARIBBEAN ECONOMIC ASSOCIATION}

September 2018

The views expressed herein are those of the authors and do not necessarily reflect the views of the Latin American and the Caribbean Economic Association. Research published in this series may include views on policy, but LACEA takes no institutional policy positions.

LACEA working papers are circulated for discussion and comment purposes. Citation of such a paper should account for its provisional character. A revised version may be available directly from the author.

(C) 2018 by Marcela Eslava and Xavier Freixas. All rights reserved. Short sections of text, not to exceed two paragraphs, may be quoted without explicit permission provided that full credit, including (C) notice, is given to the source. 
LACEA WORKING PAPER SERIES No. 0013 September 2018

Public Development Banks and Credit Market Imperfections

Marcela Eslava

Universidad de los Andes and CEDE

meslava@uniandes.edu.co

Xavier Freixas

Universitat Pompeu Fabra, Barcelona Graduate School of Economics and CEPR

xavier.freixas@upf.edu

\begin{abstract}
Which projects/firms should be the target of lending by a Public Development Bank (PDB)? What is the optimal design for the PDB's loans, and the optimal structure for delivering them? We analyze these questions in the context of a model where screening is costly to banks and underprovision of credit results from the inability of banks to appropriate the full benefits of projects they finance, more pronounced for high value projects. PDB intervention arises as a natural alternative to alleviate this inefficiency, since it originates in a failure in the private provision of credit. Lending to commercial banks at subsidized rates or providing credit guarantees, targeting the firms that generate high added value, are valid policy alternatives. Though in normal times PDB lending and credit guarantees are shown to be equivalent, lending is preferred when banks are facing a liquidity shortage, while a credit guarantees program is preferred when banks are undercapitalized. Direct lending by the PDB to the targeted industries could be superior to these subsidies to private lending, but only if the PDB's corporate governance is strong enough for public credit to respond to efficiency considerations rather than political concerns. PDB intervention naturally addresses credit underprovision stemming from failures directly affecting financial institutions, but it can also alleviate that arising from firm's moral hazard or insufficient access to collateral.
\end{abstract}

JEL Classification: H81, G20, G21, G23

Keywords: Public development banks; governmental loans and guarantees; costly screening; credit rationing.

\title{
ACKNOWLEDGEMENTS AND FINANCIAL DISCLOSURE
}

The authors are grateful to Toni Ahnert, Albert Banal, Paola Bongini, Giovanni Dell'Ariccia, Andrew Ellul, Xavier Gine, Gynogyi Lóránth, Sole Martinez Peria, Marco Pagano, José Luis Peydro, Salvatore Piccolo and the participants at the 2016 annual meeting of the Society for Economic Dynamics, the RELTIF conference, the World Bank's Macro Trade Finance seminar, and at regular 
seminars at IMF, Universitá Cattolica del Sacro Cuore, Universitat Pompeu Fabra, Universidad de Los Andes, and Banco de la Republica for their comments. Cesar Anzola has provided very useful research assistance. The authors are grateful to the Assonime/ CEPR Research Programme on Restarting European Long-Term Investment Finance (RELTIF) for financial support of the research in this paper. Xavier Freixas has benefitted from the support of Ministerio de Economia y Competividad ECO2014-55488-P, Generalitat de Catalunya and Barcelona GSE. 


\section{Introduction}

The financing of businesses by specialized public institutions is a pervasive feature of financial markets, whether in less developed economies, emerging or developed ones. Regional and global associations of Public Development Banks (PDBs) have over 280 members around the world, some of them large players in the credit markets of their respective countries. ${ }^{1}$ The activities of these institutions are varied both in scope and focus. Some of them offer financing to a broad base of clients, while many others target particular types of firms, such as Small and Medium Enterprises, startups, or nascent sectors (Figure 1). They also differ in the way they intervene: while some lend directly to businesses, others offer loans that are intermediated by private financial institutions (Figure 2). Many-73\%, according to the Global Survey of Development Banks-offer public guarantees instead of, or in addition to, providing credit.

Despite the pervasiveness of PDBs and the diversity of targets and models through which they intervene in the financial market, it is not clear which particular financial frictions are naturally addressed via the activities of a PDB, and which instrument, among those used by these institutions, is best suited for dealing with such frictions. ${ }^{2}$ Literature and practice have focused on financial market imperfections that imply credit underprovision for relatively weak projects/firms. Most PDBs, for instance, emphasize lending to SMEs (e.g. Figure 1). The theoretical justification of PDBs has had a similar focus: PDB activity has been studied as a solution for the underprovision of credit for projects with negative present value but positive externalities (Hainz and Hakenes, 2012); or for firms rationed out of credit because of moral hazard (Arping et al., 2010). ${ }^{3}$ The reason why creating a public financial institution

\footnotetext{
${ }^{1}$ Respondents of the World Bank's Global Survey of Development Banks report participations in assets of between $9 \%$ and $19 \%$ in the respective market (Luna-Martínez and Vicente, 2012). Lazzarini et al (2014) report that the Brazilian Public Development Bank, BNDES, represents over 20\% of loans in the Brazilian credit market, and amount to almost $10 \%$ of GDP.

${ }^{2}$ In "Rethinking the Role of National Development Banks" the UN (2009) defines Public Development Banks as "financial institutions set up (by the government) to foster economic development, often taking into account objectives of social development". The report goes on to state that these banks often work "mainly by providing long-term financing to, or facilitating the financing of, projects generating positive externalities". We focus, precisely, on PDB's provision of funding for businesses.

${ }^{3}$ The theoretical literature on banking also provides a number of models where relatively
} 
is the natural policy response to these underlying inefficiencies however, is not clear. Direct subsidies (e.g. tax exemptions) to projects with negative private pre-tax value but important positive externalities, for instance, seem a more natural and straightforward alternative to this particular inefficiency.

We study the optimal design of a PDB in the context of a model where banks use a costly screening technology to make credit decisions, and where they face at least some competition. Credit underprovision arises in this context as the result of the inability of banks to appropriate the full benefits of projects. High value projects are rationed out of credit because of this reason, leading to an inefficient allocation of resources to lending. PDBs could thus play a central role in the financing of high value projects. Underfinancing of high value projects, and the implication that these are optimal targets of PDB programs, contrast with the usual emphasis on relatively weak projects.

A PDB is a natural policy alternative in this context, where the underlying inefficiency resides in the banking relationship. A central contribution of this research is thus to provide a rationale for PDBs stemming from inefficiencies in the banks' supply of credit, while previous justifications of PDBs activity were based on the limitations of the demand for loans. Along the way, our model puts forward a novel source of inefficiencies in the provision of credit, and brings implications regarding the optimal design of a PDB. In particular, we ask: 1) what types of firms, if any, should be the target of particular public support programs?; 2) should the public financing of firms take the form of direct or indirect lending? 3) if it takes the form of indirect lending, should the PDB lend to private banks at subsidized rates, or rather provide public guarantees (i.e. loss sharing)?

The model considers firms that require funding in order to implement their projects. Firms belong to "industries", which are characterized by a risk profile, so that "industries" may correspond to sectors or types of firms (young, SMEs,...). Within industries, firms can be good or bad, and only good firms have positive net present value projects. The simplicity of this basic setup has the advantage of allowing us to explore the interplay between our main mechanism and other justifications for PDBs and, thus, allows for an overall perspective on the main issues at stake.

weak firms will not have access to funding in spite of the fact that the project they want to finance has a positive net present value. This is the case of firms with a limited credit history (Diamond, 1991), lack of collateral (Holmstrom and Tirole, 1997, Ruckes, 2004) or, simply, risky (Bolton and Freixas, 2000). PDBs may play a role in alleviating financial imperfections in all of these contexts. 
Figure 1: Fraction of PDB's that lend to:

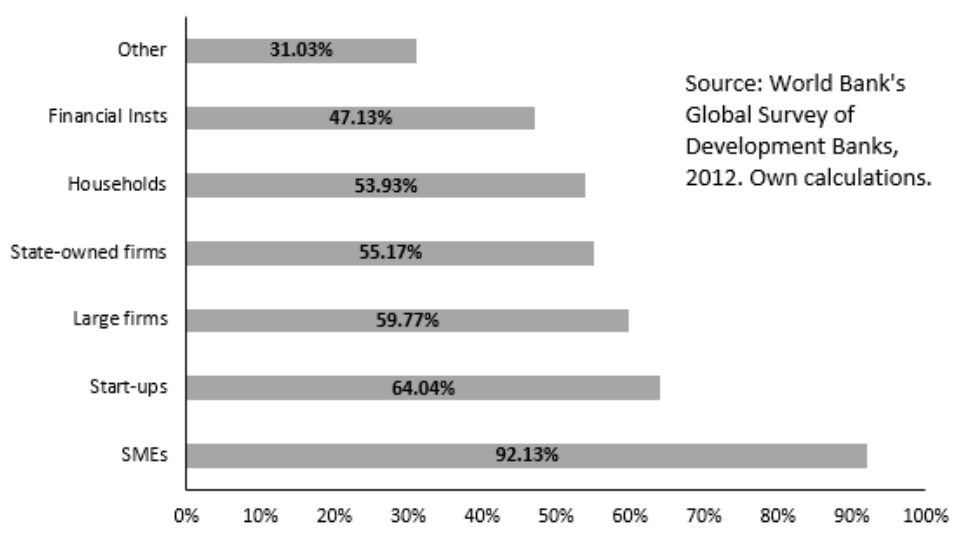

Figure 2: Fraction of PDBs that report that they lend...

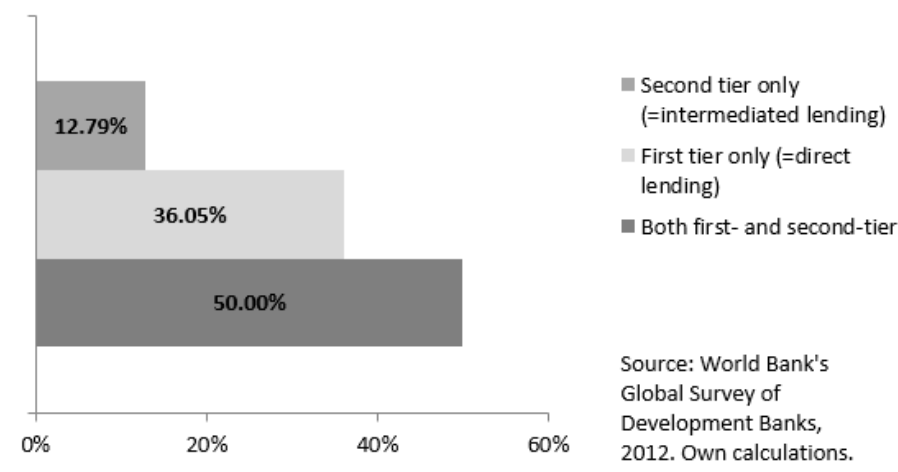


The type of a firm is not directly observable to either banks or the government. Still, commercial banks have access to a costly screening technology that yields a signal that may or may not be informative (Ruckes 2004). For any given firm, the bank and the firm will share the project's net present value. In equilibrium some good firms will be credit rationed, so that there is room for public intervention. The reason for the underprovision of screening is that banks do not take into account the rents they generate for the firm when facilitating its access to credit. Credit underprovision is more severe for types of firms for which the rents the bank cannot appropriate are larger.

Rigorously stating the issues at hand confronts us with the need to define what is specific to a PDB that makes it different, on the one hand, from a commercial bank and, on the other hand, from another government agency. We model the PDB as a bank, to the extent that it has access to the same screening technology and the same set of information that other banks have. Still, to the extent that it is publicly owned, it sources from public funds and pursues a social welfare maximization objective, although perhaps tainted by political objectives alien to the mere financing activity.

We evaluate welfare, measured by expected output net of the cost of potential government interventions, and show that intermediated public financial support can improve over the market solution. Public lending to commercial banks acts as a subsidy that induces more screening and therefore more lending. However, competition among banks affects the effectiveness of the public intervention because each bank anticipates the increased activity by competitors as a result of the subsidy. It also increases its costs, given the redundancy of screening costs in a setting where several banks screen the same borrower. The optimal subsidy balances these considerations.

We compare alternative mechanisms of public financial support, considering the effects of each mechanism on banks' behavior, as well as the implied costs of its intervention. We derive the optimal conditions for subsidies to commercial credit, as well as for public guarantees and compare the relative merits of the different arrangements. To implement this policy we consider, in turn, lending to commercial banks at subsidized rates or the provision of credit guarantees, in both cases targeting the firms that generate high added value.

Whether subsidized lending or the provision of credit guarantees is optimal depends on the specific context. In particular, we develop extensions such as liquidity or solvency restrictions. Though in normal times PDB lending and credit guarantees are shown to be equivalent, subsidized lending is 
preferred when banks face liquidity shortages, while a credit guarantees program is preferred when banks are undercapitalized. Liquidity constraints in the financial market have been put forward by Armendáriz (1999) as another justification for PDBs.

Other justifications for PDBs, residing in failures related to the demand of credit, have been put forward. We analyze how two of them interact with the credit supply failure in our baseline model. In particular, in additional extensions we bring to the table moral hazard (Holmstrom and Tirole, 1997) and insufficient collateral. We show that PDB subsidized lending and credit guarantees can be used to address these issues. The moral hazard case allows us to show that subsidies to firms conditional on successfully implementing a project have the same credit-improving effect of our supply-side instruments (interest rate subsidies to banks and public guarantees). A natural question, however, is the extent to which a PDB is the most natural agency to implement subsidies to the demand for credit.

By examining how different supply- and demand-side issues (liquidity and solvency, moral hazard, collateral) interact with our main mechanism, we shed light on optimal PDB design in a more comprehensive context than that of our baseline model.

The empirical literature has shown that financing constraints affect more starkly particular types of firms. For instance, small firms report higher financing obstacles than large firms, and the effect of these financing constraints is stronger for them compared to more established firms (See Beck et al. (2008), Beck et al. (2005); Beck et al.,(2006) and Beck and DemirgucKunt, 2006 for an overview). Nevertheless, there is also heated debate about whether the more intense obstacles to growth small firms seem to face indeed make them the optimal target of specific policies, to the extent that their potential for growth may be lower than that of larger firms. Our analysis contributes to this discussion, and related ones, by identifying features of firms that make them optimal target of policies aimed at alleviating credit rationing.

In the next section we will describe our model and the financial market imperfection it implies. Section 3 discussses PDB intervention in our baseline model, comparing direct vs indirect PDB lending, and a subsidized indirect lending program to public credit guarantees. Section 4 extends the analysis to contexts with liquidity and solvency constraints, moral hazard, and use of collateral. Section 5 is devoted to the robustness of our qualitative results. Namely, we allow for more flexible specifications for the screening 
technology and/or the type of moral hazard present. Section 6 concludes by discussing additional implications of our model and suggesting avenues for future research on the role of PDBs.

\section{The model}

Consider an economy where all agents are risk neutral, and riskless interest rates are normalized to zero. Different industries are characterized by risk parameters $p$, where $p$ captures the potential probability of success of good projects in the industry. Within industries, there are two types of firms, good and bad, in proportions $\mu$ and $1-\mu$. Good firms are at the industry's potential, facing probability of success $p$ with an implied positive net present value, while bad firms have a lower probability of success $p_{-}$, yielding negative net present value. If successful, a project undertaken by a good firm yields an outcome of $y$ per unit of investment, with constant returns to scale up to its full size $I$, so that a successful project of size $I$ yields $y I$, while a null return is obtained if the project is unsuccessful $\left(y p>1 \text { while } y p_{-}<1\right)^{4}$. The resulting cash flow is to be shared between the firm and its financier, and we assume there is an upper bound to the return of the bank. This can be easily justified as a participation constraint, where the firm, in the absence of a loan has a continuation value $E$ (e.g. equity), in which case the maximum repayment to the financier will be an amount $\bar{R} I$ satisfying $p(y-\bar{R}) I \geq E$. Alternatively, the firm's surplus $E$ can be interpreted as the cost of effort,as in section 4.

Banks have a screening technology. The type of a firm (good or bad, associated respectively with $p$ or $p_{-}$) is not observable to banks before screening. The value of $p$ and $p_{-}$, by contrast, is observed by banks and government. A bank's role in the economy is to screen firms, and thus to weed out bad firms. We initially assume that neither banks' capital nor its overall access to funding (liquidity) are constrained and address such limitations in Section

\footnotetext{
${ }^{4}$ It is easy to generalize our results so as to reinterpret $y$ as the social return rather than the private outcome, to take into account the possibility of externalities that are present in Hainz and Hakenes (2012). This very general setup allow us to interpret $y$ as the sum $y=y^{\prime}+m+e$, where $m$ are informational rents à la Holmstrom and Tirole(1997), further explored in section 4 , and $e$ is an externality, so that only $y^{\prime}$ is susceptible to be appropriated by the bank as a pledgeable cash flow.

We do not rule out potential correlations between $p, \mu$ and $y$. To keep the exposition simple, however, our notation does not explicitly recognize these potential correlations.
} 
4.1. The solvency issues, as well as moral hazard for firms and the concurrent use of private collateral, are also addressed in extensions to the model in section 4 .

\subsection{Costly Screening}

For every industry/risk $p$, by paying a sunk cost $C(q)$, that depends upon the chosen probability that the screening yields a signal, $q$, banks obtain a perfect signal on the firm's type, good or bad $\left(p\right.$ or $\left.p_{-}\right)$. We assume $C(q)$ satisfies $C^{\prime}(q)>0, C^{\prime \prime}(q)>0, C(0)=0$ and $C^{\prime}(0)=0$. That is, better quality screening is more costly, increasingly so. Because we assume the marginal screening cost is relevant, we view our framework as focusing on relationship lending, while lending based solely on automatic credit scoring is probably better characterized by a zero marginal screening cost.

Given our previous assumptions, if the bank receives a signal it will lend to good firms and deny credit to bad ones. If the bank does not receive a signal, we will assume it will not lend, i.e. that it is not profitable to lend blindly (namely, $\left[\mu p+(1-\mu) p_{-}\right] y<1$ ). Screening costs are further assumed independent of the project's size, so that no mechanical ad-hoc relationship between public credit and firm size is introduced.

\subsection{Efficient allocation}

A centralized planner that maximizes the aggregate net output will solve the following problem:

$$
\max _{q(p)} \int_{0}^{1}[\mu q(p)(p y-1) I-C(q(p))] d F(p)
$$

The solution to this problem implies that the efficient level of screening is characterized by

$$
\begin{aligned}
& \mu(p y-1) I=C^{\prime}(q(p)) \text { for an interior solution } \\
& \mu(p y-1) I>C^{\prime}(1) \text { for a corner solution } q=1
\end{aligned}
$$




\subsection{Market Equilibrium}

In our framework, because screening is not costly to firms, a firm simultaneously applies to all banks at its reach. Each bank to which a firm applies will then choose how much to screen the firm, and make offers to those that are revealed to be good. Because signals convey perfect information they are perfectly correlated across the banks that obtain the signal about a particular firm. Good firms may receive more than one offer and will then choose to borrow from the bank that offers the lowest interest rate. As shown by Broecker(1990), there is no equilibrium in pure strategies and we will therefore characterize the mixed strategies one. ${ }^{5}$

Let $N$ be the number of banks competing to supply credit to a firm. ${ }^{6}$ The probability of a bank $j, j \neq i$, not granting a loan to a good firm will be the probability of either getting a good signal but setting a repayment higher than a competitor, or getting no signal. The former occurs with probability $1-F\left(R_{i}\right)$, the latter with probability $(1-q)$. For bank $i$ quoting a repayment $R_{i}$ to be able to grant a loan, it has to be the case that the $N-1$ other banks either have obtained no signal or have quoted a higher interest rate. In turn, bank $i$ will only make an offer if it has received a good signal, which occurs with probability $\mu q$.

Consequently, when quoting $R_{i}$, a bank $i$ confronted with $N-1$ competing banks will have an expected revenue equal to:

$$
\Pi\left(R_{i}\right)=\mu I q_{i}\left(p R_{i}-1\right) \prod_{j \neq i}^{N}\left[q_{j}\left(1-F\left(R_{i}\right)\right)+1-q_{j}\right]
$$

The following result is obtained:

Proposition 1 In the mixed pricing strategy of a symmetric equilibrium, for a given level of screening $q$, banks quote repayments $R$ in the range $(\underline{R}, \bar{R})$, where $\underline{R}$ is given by:

$$
p \underline{R}=1+(1-q)^{N-1}(p \bar{R}-1)
$$

\footnotetext{
${ }^{5}$ See also Ruckes(2004). Alternative approaches such as Freixas et al., 2007 postulate that each credit application is costly for firms, which leads to a pure strategies equilibrium, at the cost of some indeterminacy.

${ }^{6}$ We do not formally model the cost to a firm of applying to a bank, which unnecessarily complicates the model. But we recognize that firms do not apply to all existing banks for the same loan, so $N$ is not really the total number of banks in the financial system, but the number of banks competing to lend to the same firm.
} 
and $\bar{R}<y$ is the maximum rate the bank can charge without violating the firm's participation constraint (or it's incentive compatibility constraint in the context of moral hazard in section 4). The bank has positive profits $\mu I q(1-$ $q)^{N-1}(p \bar{R}-1)$ even for the lowest bound $\underline{R}$.

Proof. See appendix A.

The banks' participation constraint is always satisfied (as long as $p \bar{R}>1$, which we assume) because of the convexity of $C(q)$ jointly with $C(0)=0$.

Given this equilibrium pricing strategy, it is easy to obtain the optimal level of screening in the absence of the government's intervention. The bank solves

$$
\max _{q_{i}} \int_{\underline{R}}^{y} \Pi\left(q_{i}\right) d F\left(R_{i}\right)-C\left(q_{i}\right)
$$

In the mixed strategy equilibrium bank $i$ is indifferent between the different $R_{i}$ in the support of the mixed strategy, including $\bar{R}$, so that the profit $\Pi\left(R_{i}\right)$ is independent of $R_{i}$ and equals $\Pi\left(q_{i}\right)=\mu I q_{i}(p \bar{R}-1) \prod_{j \neq i}^{N}\left(1-q_{j}\right)$ given its competitors' screening strategy $q_{j}$, and the fact that $F(\bar{R})=1$. This allows to simplify the problem and obtain the bank's optimal screening level $q_{i}$ given $q$.

$$
\mu I(p \bar{R}-1) \prod_{j \neq i}^{N}\left(1-q_{j}\right)=C^{\prime}\left(q_{i}\right) \text { for } q_{i}<1
$$

In the symmetric equilibrium this is

$$
\mu I(p \bar{R}-1)(1-q)^{N-1}=C^{\prime}(q)
$$

Notice that in the symmetric equilibrium, the corner solution $q=1$, will never hold under costly marginal screening $C^{\prime}(q)>0$.

\subsection{Credit Market Inefficiency}

Direct comparison of (1) and (4), given the convexity of $C()$ and the fact that $\bar{R}<y$, leads to a first result. 
Proposition 2 Any equilibrium solution in the credit market equilibrium leads to underprovision of screening by banks.

The inefficiency of the market equilibrium has two sources. On the one hand, screening generates an expected rent that is not fully captured by banks: the good firm that is screened and obtains funding at rate $R(p)$ obtains an additional output $y-R(p)$ with probability $p$ On the other hand, because screening by one bank is a strategic substitute to screening by another bank, the existence of a competitor reduces the probability of obtaining $R(p)$ and thus the incentives for a bank to screen.

Importantly, the presence of the externality behind this core inefficiency is not due to the use of debt as the banks' financial instrument. Other types of external financing, in particular equity or a combination of debt and guarantees, would generate the same qualitative effect so long as screening is necessary, as the financier's incentive to screen to finance would be related to the fraction of the firm's net expected profit the bank appropriates. This fraction is less than one except in the extreme case where the bank extracts all the rents from the entrepreneur. Notice that the point is quite general: it applies to any situation where the financier does not appropriate the full net present value of a successful project, so that sophisticated negotiation mechanisms between financier and firm should not eliminate the externality.

Whether the core inefficiency that we have pointed at can be partially dealt with, and how, depends upon the instruments available to the central planner. Since this inefficiency stems from the nature of the financing relationship, it is natural to consider policy options in the context of government support to the financing of businesses. In other words, instruments available in the context of a PDB. We now study some such instruments.

\section{Public credit policies}

Consider government interventions in the credit market through a PDB that supports credit for businesses. We start with the case in which the PDB intervenes by supporting commercial bank lending, a usual practice. We then discuss differences with the case where the PDB directly lends to firms. The PDB pursues the maximization of social net output rather than the maximization of bank benefits, at the cost of distortionary taxation. 


\subsection{Intermediated lending}

We start with a PDB that is able to subsidize the credit activity of banks. We later show that subsidizing commercial banks is equivalent to providing public guarantees in our basic model. We study to what extent and under which conditions it is optimal to set positive subsidies (or guarantees). ${ }^{7}$

We model the cost of raising public funds to fund the PDB intervention, stemming from the distortionary nature of taxation, as $\lambda$ per dollar spent by the PDB. We denote by $S_{C}$ the per dollar loan credit subsidy, which is conditional on the loan being issued by the commercial bank. The total cost of the loan subsidies to industry $p$ will thus be $\lambda \mu I\left[1-\prod_{i=1}^{N}\left(1-q_{i}\right)\right] S_{C}$, as the supply of credit is $\mu I\left[1-\prod_{i=1}^{N}\left(1-q_{i}\right)\right]$.

We assume the industry characteristics, $p$, and loan rates are observable. It is thus possible to implement a policy of credit subsidies that is industry (or risk) dependent, $S_{C}(p)$.

The PDB chooses its subsidy $S_{C}$, taking into account the way in which $S_{C}$ will affect the set of $\left\{q_{i}\right\}_{i=1}^{N}$ given the optimal behavior of the $N$ banks. That is, the PDB solves the following (second best) problem:

$$
\max _{S_{C},\left\{q_{i}\right\}_{i=1}^{N}} \int_{\underline{p}}^{1}\left\{\mu I\left[p y-1-\lambda S_{C}\right]\left[1-\prod_{i=1}^{N}\left(1-q_{i}\right)\right]-\sum_{i=1}^{N} C\left(q_{i}\right)\right\} f(p) d p
$$

subject to

$$
\begin{aligned}
& \mu I\left(p \bar{R}+S_{C}-1\right) \prod_{j \neq i}^{N}\left(1-q_{j}\right)=C^{\prime}\left(q_{i}\right) \text { for each bank } i \\
& S_{C} \geq 0
\end{aligned}
$$

where we have simplified notation $S_{C}(p)$ and $q(p)$ to $S_{C}$ and $q$, and where $\underline{p}$ is determined by $\mu I\left[\underline{p} y-1-\lambda S_{C}\right]\left[1-\prod_{i=1}^{N}\left(1-q_{i}\right)\right]-\sum_{i=1}^{N} C\left(q_{i}\right)=0$ and will depend upon the optimal $S_{C}^{*}$.

The solution to the PDBs problem has to take into account the fact that competition undermines the effectiveness of the subsidy to boost credit

\footnotetext{
${ }^{7}$ Of course, subsidizing banks lending does not imply banks receive a net subsidy, as the tax structure may be neutral if banks are taxed on their profits.
} 
supply. The reason is that, because the screening levels are strategic substitutes, any increase in the screening level of one bank negatively affects the incentives of other banks to screen. The PDB also considers the redundancy of screening costs by multiple banks, and the fact that its subsidies boost screening by all banks increasing the level of redundancy. The solution to this problem is summarized in the following proposition.

Proposition 3 In the symmetric equilibrium with $q_{i}=q$ for all $i$, optimal credit subsidies to banks are characterized by the following first order conditions for $S_{C}$ and $q$, respectively:

$$
\begin{aligned}
0 \geq & \lambda\left[1-(1-q)^{N}\right] f(p)+N \nu(1-q)^{N-1} \\
0= & \mu I(1-q)^{N-1}\left[\left(p(y-\bar{R})-(1+\lambda) S_{C}\right] f(p)\right. \\
& -\nu C^{\prime \prime}(q(p))-(N-1) \nu(1-q)^{N-2} \mu I\left(p \bar{R}+S_{C}-1\right)
\end{aligned}
$$

where $\nu$ is the Lagrange multiplier associated with each (symmetric) constraint 5. The implied optimal subsidy to banks is given by:

$$
\begin{aligned}
S_{C}= & \frac{1}{1+\lambda+\frac{(N-1) \lambda\left(1-(1-q)^{N}\right)}{N(1-q)^{N}}} * \\
& \left\{p(y-\bar{R})-\lambda \frac{\left(1-(1-q)^{N}\right)}{\mu I N(1-q)^{2 N-2}} C^{\prime \prime}(q)-\frac{(N-1) \lambda\left(1-(1-q)^{N}\right)}{N(1-q)^{N}}(p \bar{R}-1)\right\}
\end{aligned}
$$

for $S_{C} \leq \bar{S}$, where $\bar{S}$ satisfies the no deviation condition:

$$
\begin{gathered}
(1-q)^{N-1} \mu q(p \bar{R}+\bar{S}-1) I-C(q)= \\
=(1-q)^{N-1} \quad \mu(p \bar{R}+\bar{S}-1) I+(1-\mu)\left(p_{-} \bar{R}+\bar{S}-1\right) I
\end{gathered}
$$

\section{Proof. See Appendix B}

The intuition for (??) that characterizes the optimal $S_{C}$, is best seen through the first order conditions from which it derives (6) and (7). Equation (6) states the equalization of marginal cost and benefit of $S_{C}$ when $S_{C}>$ 0 , and implies that, at the optimal $S_{C}$, the shadow price of relaxing each constraint is $\nu=\frac{\lambda\left(1-(1-q)^{N}\right) f(p)}{N(1-q)^{N-1}}$.

Moreover, the optimal $S_{C}$ ensures that the marginal cost and benefit of each $q_{i}$ are equalized. The marginal benefit of $q_{i}$ on the welfare function is given by $q_{i}$ 's effect through the total supply of loans, valued at the associated 
externality $p(y-\bar{R})$ net of the cost $(1+\lambda) S_{C}$. The marginal benefit therefore equals $\mu I f(p)(1-q)^{N-1}\left[\left(p(y-\bar{R})-(1+\lambda) S_{C}\right]\right.$. In turn, the marginal cost of $q_{i}$ comes from its impact on the $N$ constraints, and it has a direct and an indirect component. The direct cost from the increase of $q_{i}$ equals $\nu_{i}\left(C^{\prime \prime}\left(q_{i}\right)\right)$. The indirect cost, through the impact of such an increase on $q_{j}, j \neq i$, equals $\nu_{j} \mu I\left(p \bar{R}+S_{C}-1\right)(1-q)^{N-2}$ for each of the $(N-1) j$ constraints. The equalization of these marginal cost and benefit is exactly captured by equation (7). This is most clearly seen in association with the proof in Appendix B.

As can be seen from (??), when $\mu I(1-q)^{N-1}\left[(p(y-\bar{R})] f(p)-\nu C^{\prime \prime}(q(p))-\right.$ $(N-1) \nu(1-q)^{N-2} \mu I(p \bar{R}-1)>0$, the optimal $S_{C}$ is positive. For this condition to hold, it is necessary that $(y-\bar{R})$, which measures the externality that generates credit underprovision in the market solution, is not only positive but also sufficiently large to overcome the various direct and indirect costs of the subsidy. These costs include: the $\lambda$ distortion from raising taxes and redistributing them to the private sector; the increased screening costs by both the bank that grants the loan and the other banks; and the "leak" in the subsidy that results from a dampened effect on $q$, given that every bank takes into account the strategic substitutes nature of the $q_{j}$. Given these costs of the subsidy, the second best $q$ falls short of the first best.

Our setup highlights the central role of the externality that leads to screening underprovision: financiers do not fully internalize the benefits of lending because they cannot appropriate them (i.e. $y-R>0$ ), and thus put less effort than it would be optimal in obtaining a precise signal about a potential investment project. By pinpointing this specific market failure, the analysis makes clear that a subsidy to banks, conditional on their granting a loan, is a natural intervention, though one that is costly in many dimensions, and whose effectiveness is dampened by competition across banks. The subsidy is therefore only justified for groups of firms for which credit underprovision is sufficiently severe. In particular, the analysis points out that the types of firms/loans that should be targeted are characterized by:

1. A sufficiently high externality the subsidies intend to remedy, proportional to the benefits not internalized by the bank (i.e. high $\mu \operatorname{Ip}(y-$ $R(p))$ ). Notice that our analysis characterizes the second best for every level of $y$ and $\mu$. The whole analysis carries over to any dependence of $y$ and $\mu$ on the industry characteristics, $p$, and, is, therefore, valid for any level of correlation between $p$ and $y$ on the one hand and between 
$p$ and $\mu$ on the other hand.

2. Projects with sufficiently large financing needs $I$. Notice, however, that this is true only to the extent that screening costs are either independent of project size (as specified in the basic model), or at least do not grow sufficiently fast with $I$. More precisely, if the slope of $C^{\prime \prime}(q, I)$ with respect to $I$ is greater or equal to 1 , then the optimal subsidy is not increasing in the project's size, and may actually decrease with it, a point we further discuss in section 5 .

Some of these implications challenge the conventional wisdom about valid targets for the public financing of enterprises. Credit for firms/projects with high expected returns is frequently deemed unworthy of subsidizing, under the expectation that they will be particularly well served by the market. Our results, however, point out that these projects may be, in fact, the ones where subsidies will be more effective. Low risk (high $p$ ) and high $y$ industries are, in consequence, plausible targets for the public banks support policy. Namely, sectors facing particularly dynamic demand growth, or those to firms with risky but high upside value projects should be the beneficiaries of this policy.

Our results also make it clear that subsidizing loans for large projects/firms may in fact be optimal given the large expected benefits of these loans, if the screening cost does not depend on the project size or if it increases less than proportionally with the project size. One may suspect that marginal screening costs actually decrease with project size (for instance because larger projects/firms are required to disclose more information to authorities), in which case targeting large scale projects would be particularly valuable for PDBs.

It is also clear from these results that external positive effects of a project on other firms (other than the one receiving the loan), often deemed as the justification behind the government financing of enterprises, are not a necessary condition for subsidies to be optimal. Even in their absence, the fact that the financier does not fully internalize the benefits of lending leads to loan underprovision. Of course, when positive externalities over third parties are present, they constitute an additional reason for an intervention that subsidizes loans, a point that is easily born in our model, by simply reinterpreting $y$ as the total social value of the project. 


\section{Implementation: Subsidized Lending vs. Credit Guarantees Programs}

A direct subsidy $S_{C}(p)$ per dollar of loan, conditional on the loan being granted, can be implemented by the PDB by funding credit in conditions that entail an implicit subsidy to the credit activity. A policy of subsidized funding to banks at a rate of $1-S_{C}(p)$, reaches the second best allocation as banks' expected profits will be $\mu I(1-q)^{N-1}\left(p \bar{R}+S_{C}-1\right)$.

Alternatively, the same solution can be attained by providing a public guarantee. A fully subsidized credit guarantees policy will be defined by a payment of an amount $G(p)$ to the bank in case the firm defaults. In terms of the banks' incentives, credit guarantees imply that the bank return on a loan will be $\mu I(1-q)^{N-1}[(p \bar{R}-1)+(1-p) G(p)]$. Consequently, the credit subsidy can be implemented by setting $G(p)$ so that $(1-p) G(p)=S_{C}(p)$, or $G(p)=\frac{S_{C}(p)}{1-p}$.

Still, notice that the upper bound to the possible values of $G(p)$, is lower than $\frac{\bar{S}}{1-p}$ because it provides increased incentives to deviate to the no screening strategy. This is the case because when lending to "bad" firms, the credit subsidy will be $\left(1-p_{-}\right) G>S=(1-p) G^{8}$.

\subsection{Direct lending}

A straightforward way to alleviate credit rationing stemming from failures to the supply of credit is to structure the PDB as a direct lender to businesses, with access to funding and equipped with the same screening technology other commercial banks have. The fact that the PDB is owned and managed by the government implies that it departs from private financial institutions in that it may pursue the maximization of social net output rather than the maximization of its shareholders' value, and thus provide a level of screening closer to the optimum, at the cost of distortionary taxation. However, the PDB could also potentially be subject to political pressures.

${ }^{8} \mathrm{~A}$ bank will prefer to screen firms rather than to lend to the average firm provided:

$$
\begin{aligned}
& (1-q)^{N-1} \mu q(p)(p \bar{R}+(1-p) G(p)-1) I-C(q(p)) \geq \\
& (1-q)^{N-1}\left(\mu(p \bar{R}+(1-p) G(p)-1) I+(1-\mu)\left(p_{-} \bar{R}+\left(1-p_{-}\right) G(p)-1\right) I\right)
\end{aligned}
$$

We will assume this condition is satisfied, which implies $G(p)$ is lower than the threshold $\overline{G(p)}$, for which the equation holds with equality. 
Abstracting first from political interferences, a policy of direct lending implies the PDB will become an additional player and, thus, compete with commercial banks. Because it enters a profitable market, there will be a positive side of direct lending if it plays the same strategy as other banks and obtains a positive profit equal to $\mu I(p \bar{R}-1) q(1-q)^{N-1}-C(q)$ : that profit will be valued at $1+\lambda$ per dollar, as PDB's profits replace distortionary taxation. Second, because its objective function takes into account the total cash flow $y$ rather than the pledgeable fraction $\bar{R}$, the PDB will set a level of screening-that we denote $q_{P D B}$-higher than its competitors. By so doing, the PDB reduces the welfare loss from the externality $p(y-\bar{R})$, at the direct cost $C\left(q_{P D B}\right)-C(q)$ and the indirect cost of de-incentivizing private lending because screening levels are strategic substitutes. Every commercial bank $i$ will now face a lower expected revenue of its screening, that becomes $\mu I(p \bar{R}-1) q_{i}\left(1-q_{P D B}\right) \prod_{j \neq i, j \neq P D B}^{N}\left(1-q_{j}\right)$ for bank $i$, and, consequently will reduce their level of screening. Because the maket solution $q_{P D B}=q$ is still possible, it is clear that by choosing the optimal $q_{P D B}^{*}$, the total amount of production will be increased. Thus, in the absence of political pressures and when access to the same screening technology is posible, direct lending dominates the market solution.

The comparison with indirect lending is more involved, as indirect lending also dominates the market equilibrium. While a subsidy would increase the level of screening of all commercial banks, direct lending will decrease it. The cost of indirect lending may be higher as all banks are subsidized while in the direct lending only the PDB losses (if any) may have to be subsidized. Finally, indirect lending leads to an increase of the cost of screening equal to $N\left(C\left(q_{s}\right)-C\left(q_{0}\right)\right)$, where $q_{s}$ is the equilibrium level of screening when the subsidy is $S$ and $q_{0}$ is the market level of screening, while direct lending will increase the PDB screening cost by $C\left(q_{P D B}\right)-C\left(q_{0}\right)$. That is, direct lending has the advantage of avoiding screening duplication induced by the public policy, so that this cost will be higher for indirect lending for given $q_{s}=q_{P D B} \cdot$

Political and other biases reduce the value of direct lending vis-a-vis the intermediated model, since in the latter it is profit-maximizing private banks, not subject to political pressures, who screen firms and decide who to lend to. There is nowadays an abundant body of empirical evidence that points at cases where credit allocation by PDBs is consistent with the PDB following 
political considerations rather than seeking to maximize efficiency. Direct lending by PDBs has been found to increase in election years, and to be targeted to politically valuable costumers or regions, especially in election years (Carvalho, 2014; Cole, 2009; Dinc, 2005; Khwaje and Mian, 2005; Lazzarini et al, 2014; Sapienza, 2004). ${ }^{9}$ Such evidence makes intermediate lending more attractive as an alternative to direct lending by the PDB. This is why we concentrate here on indirect interventions.

Our framework also allows to address the highly debated issue regarding whether PDB activities complement or substitute commercial banks' lending. The results may be quite different depending on whether we consider direct or indirect lending. Because of the additional competition, direct lending will reduce commercial banks' profits, and reduce their probability of granting a loan. That is, direct lending by the PDB implies substitution.

Indirect lending, instead, provides additional incentives to banks and therefore complements their activity by either supplying funds at a lower cost or by providing guarantees. Still, providing funds at a lower cost may be expensive, because the subsidies channeled through the PDB may merely create rents for banks and firms, without solving the underprovision of credit if it does not affect the banks marginal cost of funds. In other words, in order to increase the level of screening from $q$ to $q+\Delta q$, subsidies will be offered not only on the additional loans $(\mu \Delta q)$, but also on the loans the bank would have granted anyway ${ }^{10}$. Since the PDB takes into account these costs and benefits of the policy, if the solution to the PDB problem involves $S>0$, then it must the the case that the cost of subsidizing the loans that the banks would have granted without the policy is lower than the social benefit of the resulting increased lending. If this were not the case, the PDB would find it optimal choose $S=0$, with $q=q_{0}$, an option available to it. That is, indirect PDB lending partly complements and partly substitutes commercial lending, with the balance between these two dimensions being socially beneficial.

One additional dimension over which PDB intervention is expected to complement private financing is the provision of long term credit (Armendáriz,

\footnotetext{
${ }^{9}$ One possible reason for the inefficiency of direct lending is the institutional weakness leading to the direct lending process not being autonomous with respect to the government and the objectives and constraints of its leaders. Other causes are corruption and more stringent legal constraints that bind public agencies compared to private institutions.

${ }^{10}$ Notice that additional taxes to banks' profits, that are not conditional on the bank granting intermediated loans may be used to counteract this unintended consequence of the subsidies policy.
} 
1999; The World Bank, 2016; Smallridge and De Olloqui, 2011). This focus is also supported by our analysis, to the extent that long term credit entails much higher screening costs than short term credit, since long term lending implies risks that demand more careful evaluation of the loan. Moreover, projects that have particularly high value will frequently require longer term financing than others (The World Bank, 2016). In our analysis, the PDB precisely focuses on dealing with the underfinancing of projects of particularly high value, a problem that arises in the presence of positive marginal screening costs and that is more acute when these costs are higher. ${ }^{11}$

\section{Extensions}

We have so far discussed optimal PDB design when its intervention seeks to alleviate credit underprovision originated in the inability of commercial banks to appropriate the full benefits of the loan. But this goal may interact with other goals and constraints for the PDB. In particular, PDBs are frequently seen as playing a crucial countercyclical role (Luna-Martinez et al., 2012); as tools to alleviate credit underprovision from moral hazard on the side of firms (Arping et al. 2010); or as tools to boost credit to projects that have negative net present value but high positive externalities on economic activity (Hainz and Hakenes, 2012). Taking into consideration these other motivations for PDBs and understanding their implications for optimal PDB design requires more elaboration. Such is the goal of this section. We start by examining supply side shortages, and then move to demand-side failures underlying credit underprovision.

\subsection{Supply side shortages}

The discussion so far has assumed banks could issue both debt and equity in a perfect market so that the structure of their liabilities has been irrelevant, as it occurs in a Modigliani-Miller framework. Still, under stress, and particularly during a financial crisis, banks may face serious restrictions to either

\footnotetext{
${ }^{11}$ It has also been suggested that one of the reasons why PDBs are particularly useful when coming to long-term financing is their greater ability, compared to private bank, to rely on long term financing (Smallridge and De Olloqui, 2011). In our analysis, this would imply the PDB has a lower cost of funding in this segment of the market which would then decrease the cost to tax payers.
} 
refinance their debt or issue stock. Such limitations will have an impact on the supply of loans, and therefore, when this is the case, on the role the PDB may play.

We will now extend our framework to show how public funding to banks and credit guarantees will help ease liquidity and capital constraints and may, thus, be particularly valuable during times of crises characterized by these shortages. Interestingly, while in a perfect capital market subsidized lending and credit guarantees had the same impact, depending on the prevailing constraint, debt refinancing or capital shortages, they will have different impacts.

\subsubsection{Liquidity}

A limited access to funds by banks can easily be incorporated in our bank model. A monetary contraction or a regulatory constraint on banks' funding implies an increase in the equilibrium cost of funds for banks, that will now equal $r$. The first order condition that determines banks' level of screening in the symmetric equilibrium, will now be the following:

$$
\mu I[p \bar{R}-(1+r)](1-q)^{N-1}=C^{\prime}(q)
$$

Unsurprisingly the liquidity shortage leads to a reduction in the level of screening. Suppose that the PDB is able to continue lending at zero cost of funds (for instance, because it has access to credit by multilaterals). The second best program will now lead to an equivalent first order condition:

$$
\begin{aligned}
S_{C}= & \frac{1}{1+\lambda+\frac{(N-1) \lambda\left(1-(1-q)^{N}\right)}{N(1-q)^{N}}} * \\
& \left\{p(y-\bar{R})+r-\lambda \frac{\left(1-(1-q)^{N}\right)}{\mu I N(1-q)^{2 N-2}} C^{\prime \prime}(q)\right. \\
& \left.-\frac{(N-1) \lambda\left(1-(1-q)^{N}\right)}{N(1-q)^{N}}(p \bar{R}-1-r)\right\}
\end{aligned}
$$

That is, the optimal subsidy is augmented when the PDB can source a lower cost than is possible for commercial banks, as is the case in liquidity crunches. This is true not only because the PDB perceives a lower cost of 
any credit activity, but also through feedback effects, captured by the last term in $S_{C}$.

In this context, subsidized lending and credit guarantees are not equivalent any longer. While the expected per-dollar-of-loan cost of a credit guarantee will be $\lambda S_{C}$, the cost will be equal to $\lambda\left(S_{C}-r\right)$ when the PDB issues a credit line and benefits from the favorable spread in the cost of funds, reducing the cost of its intervention to taxpayers.

\subsubsection{Capital Shortages}

We have so far assumed away minimum capital requirements, which are in fact a prevalent characteristic of financial regulation. The banks' lack of regulatory capital, characteristic for instance of a credit crunch (See Bernanke and Lown, 1991), may also impose a limit to the banks' lending capacity. Denoting by $\beta$ the risk weight that the regulator has associated to lending to firms, the constraint will be:

$$
\int_{p^{*}}^{1} \beta \mu I \frac{1-(1-q(p))^{N}}{N} f(p) d p \leq E
$$

as $\mu I \frac{1-(1-q(p))^{N}}{N}$ is the amount of credit granted by a bank to firms of type $p$ in the symmetric equilibrium. Notice that the derivative with respect to $q(p)$ is $\beta \mu I(1-q(p))^{N-1} f(p)$.Denoting the corresponding Lagrange multiplier by $\phi$, this implies that the new first order condition for $q$ in the market equilibrium is:

$$
\begin{aligned}
\mu I(p \bar{R}-1)(1-q)^{N-1}= & C^{\prime}\left(q_{i}\right)+\phi \beta \mu I(1-q(p))^{N-1} \\
& \text { or } \\
\mu I\left(p \bar{R}+S_{C}-1-\phi \beta\right)(1-q)^{N-1}= & C^{\prime}\left(q_{i}\right)
\end{aligned}
$$

The regulatory capital constraint constitutes a shadow cost of funds, which reduces the optimal amount of lending in the market solution.

A credit guarantees program is an interesting policy alternative, provided that the regulatory treatment of guaranteed loans recognizes the fact that guarantees reduce the loss given default on loans. ${ }^{12}$ In this world, public

\footnotetext{
${ }^{12}$ The experience of Colombia is particularly illustrative: the number of guarantees provided by the program of public credit guarantees more than doubled after the finan-
} 
guarantees soften the regulatory capital constraint. Because a credit guarantees program reduces the banks' risk for the targeted loans, the risk exposure is reduced from $I$ to a fraction $\left(1-\frac{G(p)}{I}\right) I$, if $\frac{G(p)}{I}$ is the fraction of losses the PDB commits to cover. That is, starting from a world where the capital constraint binds $\left(\int_{p^{*}}^{1} \beta \mu I \frac{1-(1-q(p))^{N}}{N} f(p) d p=E\right)$, this public guarantees program transforms the constraint in $\int_{p^{*}}^{1} \beta \mu I\left(1-\frac{G(p)}{I}\right) \frac{1-(1-q(p))^{N}}{N} f(p) d p \leq E$, thus being equivalent to an injection of capital equal to $\mu G(p) \frac{1-(1-q(p))^{N}}{N}$ and allowing an effective increase in total lending.

By contrast, subisdized intermediated loans are less effective in the world where capital constraints bind, and thus the total amount of credit cannot be increased. This is the world where $\phi>0$ and $\int_{p^{*}}^{1} \beta \mu I \frac{1-(1-q(p))^{N}}{N} f(p) d p=E$. Subsidized lending will, in this case, increase screening of some types at the expense of reducing screening for other types.

Generalizing our analysis, macroeconomic conditions may have exactly the same effect as a liquidity or capital shortages. For instance, recessions may be times of particularly acute liquidity and capital restrictions for banks, especially when associated with financial crises. In any situation where the cost of bank funds increases while the PDB is not affected in a similar way, the difference creates a wedge, $\Delta r$, between the two that makes PDB lending comparatively less costly and it becomes efficient for the PDB to expand its credit programs. Our framework supports the common wisdom that public financing by PDBs lending could play a countercyclical role (Luna-Martinez et al., 2012).

\subsection{Demand-side failures}

\subsubsection{Firms' Moral Hazard}

We now extend our framework to consider an alternative justification of PDBs based on moral hazard as put forward by Arping et al.'s (2010). When firms engage in moral hazard behavior, as in Holmström and Tirole (1997), the resulting equilibrium is characterized by an underprovision of credit.

cial regulator issued a decree (Decree 686, 1999) deeming these guarantees "admisible". Admisibility allowed financial institutions to use the guaranteed amounts towards their capital requirements (Arraiz et al. 2014).

Obviously the decrease in capital, as in any credit risk mitigation measure, will depend upon the credit rating of the PDB. When the PDB has a poor rating, credit guarantees issued by the PDB may have a very limited impact. 
The basic Holmström and Tirole assumptions can be easily brought into our model, adding moral hazard to our baseline source of credit underprovision. We do so by assuming that firms are able to choose a project that yields private benefits $B$ at the expense of a lower probability of success, $p-\Delta p$ (or $p_{-}-\Delta p$ for bad firms). Projects by firms that engage in moral hazard behavior yield a negative expected return, even if the firm is good: $(p-$ $\Delta p) y+B<1$

For a given repayment $R$, the firm will choose the high probability of success project, rather than enjoying the private benefits if and only if:

$$
p(y-R) I \geq(p-\Delta p)(y-R) I+B
$$

that is,

$$
\begin{aligned}
R & \leq y^{\prime} \\
\text { where } y^{\prime} & =y-\frac{B}{I \Delta p}
\end{aligned}
$$

Denoting as $[\underline{R}, \bar{R}]$ the range of interest rates posted by banks in a mixed strategy equilibrium without moral hazard, it is clear that moral hazard is irrelevant if $\bar{R} \leq y^{\prime}$. Our baseline second best solution and the associated analysis of optimal PDB design continue to hold in that case.

We therefore focus on the case $\bar{R}>y^{\prime}$. In this case, banks in a decentralized equilibrium will never lend at a rate higher than $y^{\prime}$. The mixed strategy equilibrium with moral hazard will therefore have a support $\left[\underline{R}^{\prime}, y^{\prime}\right]$ where $\underline{R}$ is endogenously determined by the equivalent of (2), so that $p \underline{R}^{\prime}=$ $1+(1-q)^{N-1}\left(p y^{\prime}-1\right)$. Compared to an equilibrium in absence of moral hazard, this implies a reduction of the banks' expected profits and, consequently, a lower $q_{i}$.

A subsidy $S_{C}$, as previously explored, changes the equilibrium mixed strategies, ameliorating credit underprovision from both sources (inappropriability of the full benefits by the bank, and moral hazard). This is the case as the indifference in the expected outcome of the different strategies (following a logic and proofs analogous to those of Proposition 1) implies

$$
p \underline{R}=1+(1-q)^{N-1}\left(p y^{\prime}+S_{C}-1\right)-S_{C}
$$

and

$$
F(R)=\frac{1}{q}\left\{1-(1-q)\left[\frac{p y^{\prime}+S_{C}-1}{p R+S_{C}-1}\right]^{\frac{1}{N-1}}\right\}
$$


Notice, from the first order condition 3 expanded with the subsidy and the consideration of moral hazard, that for $1>q_{i}>0, C^{\prime}\left(q_{i}\right)>0$ implies $p y^{\prime}+S_{C}-1>0$, and this, in turn using (13) implies $p \underline{R}+S_{C}-1>0$, so that the interval $R \in\left(\underline{R}^{\prime}, y^{\prime}\right)$ is never empty.

An alternative, apparently more direct, way to address the part of credit underprovision arising from moral hazard is a direct subsidy to the firm conditional on the success of the project. This is equivalent to the PDB (or, more generally the government) offering firms a performance premium, so as to provide them with the incentives to choose the project with the higher probability of success ${ }^{13}$. Denote this performance premium by $I P_{F}(p)$. The moral hazard constraint (10) becomes $\left[y+P_{F}-R\right] I \geq \frac{B}{\Delta p}$, or $R \leq y^{\prime}+$ $P_{F}$., In this case, the $\mathrm{PDB}$ is able to quote an interest rate in the range $\left(R\left(p_{F}\right), y^{\prime}+P_{F}\right)$. In other words, the subsidy to the firm is passed back to the bank that in equilibrium will quote higher interest rates.

As the subsidies to the firm and to the bank are not incompatible, it is possible to restate the PDB maximization problem as follows, combining these two mechanisms:

$$
\begin{aligned}
& \max _{S_{C}, P_{F}, q, p^{*}} \int_{p^{*}}^{1}\left\{\mu I\left[1-\prod_{i=1}^{N}\left(1-q_{i}\right)\right]\left[p y-1-\lambda\left(S_{C}+p P_{F}\right)\right]-\sum_{i=1}^{N} C\left(q_{i}\right)\right\} f(p) d p \\
& \mu I\left(p\left(y^{\prime}+P_{F}\right)+S_{C}-1\right) \prod_{j \neq i}^{N}\left(1-q_{j}\right)=C^{\prime}\left(q_{i}\right) \text { for each bank } i \\
& S_{C} \geq 0 ; \quad P_{F} \geq 0 ; \quad 1 \geq q ;
\end{aligned}
$$

The expression shows that, perhaps surprisingly, the two subsidy policies are equivalent: only the optimal amount of $S_{C}+p P_{F}$ will be determined. The equivalence occurs because of competition, which forces banks to transfer a fraction of any subsidy they receive to clients. A conditional subsidy to the firm of $P_{F}$ implies the bank is able to increase its lending rate by this amount, so it is equivalent to an unconditional subsidy to bank lending of $p P_{F}$.

The logic underlying the equivalence between $S_{C}$ and $P_{F}$ is not unique to the moral hazard case. Even in absence of moral hazard, a performance premium makes borrowing to implement the project more attractive to firms,

\footnotetext{
${ }^{13}$ Notice also that a pure subsidy to a firm, unconditional on the success of the project would have no effect on the moral hazard constraint, as it would be added both to the left and right hand side of condition (10)
} 
allowing for higher interest rates and therefore more incentives for banks to lend. That is, performance premia also have the effect of ameliorating credit underprovision arising from our core externality. Though understanding this equivalence is important, subsidies to firms are not the natural policy tool for a PDB.

\subsubsection{Private collateral}

The existence of private collateral constitutes an important extension to our analysis. This is so because, as we will see, private collateral may substitute for screening.

To begin with, notice that, although both private collateral and public guarantees allow the bank to recover a fraction of the loan in case the borrower defaults, in the collateral case it affects the borrower itself, with completely different implications on its incentives to apply for a loan. Because the borrower is not affected by public credit guarantees, their existence will increase the banks' expected return and, therefore, it will also rise the screening level. As mentioned, credit guarantees-when optimal-play the role of a subsidy to lending. Collateral, instead, will play a key role in the firms' self selection.

So far, we have assumed that a bank receiving no signal on a firm will not finance it. Nevertheless, this need not be the case if the firm is to post collateral. ${ }^{14}$ In this case, however, it is possible that the amount of the loan the firm obtains is constrained by the availability of collateral and the firm's project has to be downsized. We extend now our analysis to the case where agents are endowed with some exogenously given amount of collateral, which we denote $V .^{15}$

As it is standard, we will assume collateral is costly, so that the $V$ value of the asset to the bank is lower than its value to the firm, $(1+\delta) V$, with $\delta>0$. In the present setup, collateral will play two related roles: as a signalling device and as credit risk mitigation.

Signalling allows good firms to separate from bad firms, if the latter are not willing to post collateral and, therefore, its use provides a substitute for screening.

\footnotetext{
${ }^{14}$ If property rights do not provide legal certainty to pledging and repossession, however, collateral based credit may be quite limited.

${ }^{15}$ This amount will depend, among other factors, upon the legal and institutional features of the economy.
} 
Let $R_{V}(p, V)$ be the per dollar repayment on a loan $I$ collateralized with an asset valued $V$ to the bank. Because firms know their types ${ }^{16}$, when the value of collateral $V$ is larger than some threshold, only good firms will be ready to pledge their collateral. Define $\nu_{B}$ as the collateral per dollar of loan that leaves the bad firms indifferent between a partially collateralized loan and abstaining from applying for a loan. That is, $\nu_{B}$ satisfies the following condition:

$$
p_{-}\left(y-R_{V}(p, V)\right)-\left(1-p_{-}\right)(1+\delta) \nu_{B}=0
$$

Then, any loan contract with a collateral to loan ratio $\frac{V}{I}$ higher than $\nu_{B}$ will deter bad firms from applying for a loan. Because downsizing has an opportunity cost for the firms, efficient signalling contracts will be characterized by the maximum loan per unit of collateral, that is the minimum $\frac{V}{I}$ that satisfies $\nu_{B} \leq \frac{V}{I}$. This implies the good firm individual rationality constraint is trivially satisfied, for any contract characterized by a collateral to loan ratio $\nu_{B}$. This ratio, jointly with $V$ will determine the maximum size $I$ at which the firm will be able to develop its project.

Notice that whenever $\nu_{B}<\frac{V}{I}$ it is unnecessary for banks to screen firms for collateralized lending. The use of collateralized loans implies that all good firms have their projects funded so that there is no credit rationing due to banks' insufficient screening.

Still, depending on the availability of collateral $V$ and on the cost $(1-p) \delta$ of pledging it, banks' screening is more efficient. Firms prefer to be screened by the banks if, by so doing, they generate higher profits than by pledging their collateral, that is:

$$
p(y-R(p)) I^{*}>p\left(y-R_{V}(p)\right) \frac{V}{\nu_{B}}-(1-p)(1+\delta) V
$$

where $I^{*}$ is the size of the loan required to finance the project without downsizing. The condition is obviously met when collateral is scarce. Still, even if collateral is plentiful, if its cost $\delta$ is sufficiently high in comparison to the cost of screening, condition(15) is also fulfilled ${ }^{17}$. In the following we will assume the condition is satisfied, so that both firms and banks are

\footnotetext{
${ }^{16}$ If firms do not know their type, under our assumption of an expected negative present value for the average firm, $\left(\mu p+(1-\mu) p_{-}\right) y<1$, if banks break even, firms will make losses and, therefore will abstain from asking for a collateralized loan.

${ }^{17}$ Because in equilibrium the per dollar expected profits should be equal across banks, we have $p R(p))-\frac{C(q(p))}{\mu I}=p R_{V}(p)+(1-p) \nu_{B}$

A sufficient condition for the above inequality to be satisfied is:
} 
better off if the bank screens. Notice, though, that when this condition is not satisfied, and the firm prefers to borrow collateralized because it has sufficient collateral, the policy implication is clear: the PDB should abstain from any intervention.

In the following, we focus on the case where, first, banks invest in screening, and, if no signal is obtained, they offer the firm the possibility of a smaller collateralized loan that is only attractive to good firms. We will assume that the firm has the same probability $\frac{1}{N}$ to borrow collateralized from any bank. When this is the case, the objective function of the bank is modified. If the bank obtains a non-informative signal, which occurs with probability $(1-q)$, it will still be able to grant an amount $\frac{V}{\nu_{B}}$, partially collateralized by $V$ which is sufficient to discourage bad firms . Bank $i$ profits will now become:

$\max _{q_{i}}\left[1-q_{-i}\right]^{N-1}\left\{\mu I q_{i}(p \bar{R}-1)+\frac{1}{N}\left(1-q_{i}\right)\left[\left(p R_{V}+(1-p) \nu_{B}\right)-1\right] \frac{V}{\nu_{B}}\right\}-C(q)$

The first order condition that determines the level of screening will be:

$$
\left.\left[1-q_{-i}\right]^{N-1}\left\{(p R(p)-1) I^{*}-\frac{1}{N}\left[\left(p R_{V}+(1-p) \nu_{B}\right)-1\right] \frac{V}{\nu_{B}}\right\}=C^{\prime}(q)\right)
$$

Consequently, the introduction of collateral decreases $q$ through the "spare tire" effect of collateralized lending when the bank obtains no signal. Of course, this does not mean that a policy promoting the use of collateral by protecting creditors' rights to repossession should not be implemented. It simply states that, if collateral lending is profitable, i.e. $p R_{V}+(1-p) \nu_{B}>1$, then the existence of collateral has a cost in terms of relationship banking and in the lower level of screening it generates. The result is in line with Manove et al.(2001) model of "lazy banks" and has competition policy and regulatory implications.

$$
\frac{C(q(p))}{\mu I} \leq(1-p)(1+\delta) \nu_{B}
$$

because, in this case, the firm prefers an uncollateralized loan, even in the absence of any downsizing, simply because the expected cost to the firm of losing its collateral is higher than the screening cost to the bank.

Still, this is only an extreme sufficient condition when, in fact, downsizing has an opportunity cost that makes our hypothesis of efficient screening even more natural. 
Our results shed light on two major regulatory issues. First it emphasizes the importance of a highly competitive market for collateralized loans, where barriers to entry (legal or related to the register of property rights) may be easily eliminated. Indeed, the lower the banks' market power in the collateralized market, $p R_{V}+(1-p) \nu_{B}-1$, the higher the level of screening in the uncollateralized segment. Second, regarding banks capital regulation, it implies that collateralized loans should have a very low capital charge, in line with Basel II and III.

Thus, overall, the introduction of collateralized lending will, on the one hand, increase the total output but, on the other hand, diminish the bank's incentive to screen.

Because the subsidy in case of a collateralized loan is not justified, the second best problem becomes:

$$
\begin{aligned}
& \max _{S_{C}, q} \int_{\underline{p}}^{1} \mu\left\{\left[1-\prod_{i=1}^{N}\left(1-q_{i}\right)\right]\left(p y-1-\lambda S_{C}\right) I\right. \\
& \left.+\prod_{i=1}^{N}\left(1-q_{i}\right)\left(p(y-1) \frac{V}{\nu_{B}}-(1-p) \delta V\right)-N C(q(p))\right\} f(p) d p \\
& \text { s.t. } \\
& {\left[1-q_{-i}\right]^{N-1}\left\{\left(p \bar{R}+S_{C}-1\right) I^{*}-\frac{1}{N}\left[\left(p R_{V}+(1-p) \nu_{B}\right)-1\right] \frac{V}{\nu_{B}}\right\}=C^{\prime}((\mathbf{1} \mathbf{y})} \\
& S_{C}(p) \geq 0 ; \quad 1 \geq q(p) ;
\end{aligned}
$$

The optimal subsidy is given by the following formula. (see Appendix C for its derivation):

$$
\begin{aligned}
& S_{C}^{\mathrm{col}}=\frac{1}{\left(1+\lambda+\frac{(N-1) \lambda\left(1-(1-q)^{N}\right)}{N(1-q)^{N}}\right) I} * \\
& \left\{\left[\left(p(y-\bar{R}) I-\Gamma_{1}+\Gamma_{2}\right]-\lambda \frac{\left(1-(1-q)^{N}\right)}{\mu N(1-q)^{2 N-2}} C^{\prime \prime}(q)\right.\right. \\
& \left.-\frac{(N-1) \lambda\left(1-(1-q)^{N}\right)}{N(1-q)^{N}}\left((p \bar{R}-1) I-\Gamma_{2}\right)\right\}
\end{aligned}
$$

where $\Gamma_{1} \equiv(p y-1) \frac{V}{\nu_{B}}-(1-p) \delta V$ and $\Gamma_{2}=\frac{\left[\left(p R_{V}+(1-p) \nu_{B}\right)-1\right] V}{N \nu_{B}}$. 
When comparing the level of the subsidy when there is no collateral, (8) with the one obtained in the presence of collateral (18), notice first that for $\Gamma_{1}=\Gamma_{2}=0$, the formula of (18) is precisely the one of (8).The additional term $\Gamma_{1}$ corresponds to the increase in welfare created by collateral: a good firm that is unlucky on its screening, will still be able to get a loan $\frac{V}{\nu_{B}}$, so the social cost of the underprovision of screening is not as high as before. On the other hand, $\Gamma_{2}$ is the profit on a collateralized loan that has a negative impact on the level of screening, because of the spare tire effect. This implies that, in the presence of collateral, a zero screening level could be attained in equilibrium, in spite of the zero marginal cost of screening if the bank margin $(p \bar{R}-1)$ is small. As can be seen from the sign in (18), while the first effect $\Gamma_{1}$ decreases the subsidy by decreasing the cost of a good firm not beeing able to finance its project at the right scale, the second effect depresses the level of screening and it will lead to a positive impact on the optimal subsidy so as to increase it. In the case of pure competition, $\Gamma_{2}=0$, the subsidy will always be lower than the one in the case of no collateral (8) as only the first effect will take place.

This expression allows us to identify the industries that should be targeted. Notice that if $q>0$, then $(p \bar{R}-1) I-\Gamma_{2}>0$, (as otherwise the profits on collateralized loans being higher firms would prefer $q=0)$. Consequently,

only industries characterized by a sufficiently large $\left[\left(p(y-\bar{R}) I-\Gamma_{1}+\Gamma_{2}\right]\right.$ will be susidized.

For a given expected profit, our findings square with the argument that firms lacking the possibility of collateralizing their loans, or facing limited competition in the collateralized loan market (with $-\Gamma_{1}+\Gamma_{2}$ low in absolute value or even positive), are desirable targets of public financing. In particular, low available collateral $V$ and high minimum required collateral $\nu_{B}$ make it more likely that the above condition is fulfilled. Young firms, and those in sectors holding little pledgeable assets (such as services), are likely examples of such targets.

\section{Robustness}

At this stage it is interesting to examine how robust are our qualitative results. We study how results are affected by different changes in our basic assumptions.

\section{- Alternative screening technology}


Would the same results hold if, instead we had a screening technology based on an imperfect signal? The answer is affirmative provided the quality of the signal is costly.

Suppose that screening will provide a signal $s$ on the firms' distribution of cash flows $y$, generating an ex post distribution with density function $f(y \mid s)$, which is informative about $y$ in the sense of the Monotone Likelihood Ratio Property (MLRP), so that high signals imply a higher probability mass on the high cash flows. When this is the case, the optimal decision for the bank will be to lend whenever the signal is higher than some threshold $s^{*}$. The bank choice of screening corresponds then to the precision of the signal $s$, ranging from a perfect signal $y=s$ at a high cost to no precision at all (in which case $f(y \mid s)=f(y))$ at zero cost. The precision level will result from profit maximization and, again, will not take into account the benefits accruing to the firms of the choice of precision, $p(y-R(p))$ that generates the externality. Consequently, the resulting equilibrium will be characterized by an underprovision of credit and a policy of subsidized loans will improve the allocation.

Still, the analysis of competition will lead to different conclusions, because bad firms will have a chance to be granted credit. This implies, as in Broecker(1990) that when the population of banks increases, the chances of bad firms to obtain credit increases and, for a given interest rate, the average return on a bank loan may decrease.

\section{- Screening costs and interest rates that depend on loan size}

We have assumed that the screening cost does not depend upon the size of the project and of the loan. This seems a reasonable yet critical assumption. Indeed, if the screening costs were to be proportional to the projects' size, it would imply that size is irrelevant in the screening decision and small firms would have the same chances of being financed as large firms. As a result, the optimal subsidy would no longer depend on the size of the project. This is easily seen by assuming that the screening cost is given by $C(q)=I c(q)$, so that $C^{\prime \prime}(q)=I c^{\prime \prime}(q)$. Introducing this expression in equation (8) that defines the optimal level of the subsidy, it is clear that $I$ disappears from this expression.

\section{- Industry specific screening costs}


Finally, it is often argued that screening might be more or less costly in different industries (representing, in our framework, groups of firms that share some characteristic).. This is the case, for instance, for SMEs. As stated by Beck et al. (2008, p.1-2)"Both high transaction costs related to relationship lending and the high risk intrinsic to SME lending explain the reluctance of financial institutions to reach out to SMEs". In addition, the scarcity of reliable data on SMEs and the possible manipulation of their financial statements make screening more costly. The same arguments should apply for young firms as well as for young industries. In our model, if repeated lending to the same industry decreases the screening cost, the optimal subsidies should also progressively decrease. When this is the case, subsidies should be directed to "nascent" industries and should disappear from "senescent" ones.

We have considered the screening costs faced by banks and the expected value of projects as exogenous to the banks' activities. However, some public development banks also have consultancy activities directed to both firms and banks. This is the case, for instance, of the Business Development Bank of Canada or Bancoldex (Colombia). If the PDB is able to decrease the cost of screening (e.g. by improving accounting standards, or corporate governance), this will increase access to credit, and should therefore decrease subsidies for screening to the industry and its cost.

\section{Conclusion}

This paper proposes a framework to analyze the role of PDBs. We argue that the main justification for this type of institution is not to be found in either the positive externalities of some negative net present value projects or on the firms' limits to contract upon their future actions and the moral hazard that those limits imply. Instead, we propose that the main role PDBs may play is to help deal with financial market imperfections. The fact that financial institutions face potentially large screening costs when lending to firms makes the environment we model a natural candidate to analyze the merits of different possible PDB arrangements.

As we show, screening costs imply that some positive net present value firms are suboptimally deprived from funds, thus introducing a major friction in the credit market. This result implies that (inefficient) underfinancing is particularly acute and costly for society in the context of high net present 
value projects, contrary to conventional wisdom. This finding shifts the spotlight from the usual focus on public financing for risky small business that lack sufficient collateral, those with a limited credit history, or those with a low present value. Instead, our results highlight that PDBs should provide incentives for commercial banks to increase their screening of highly profitable firms/projects. When banks are unconstrained, this could be done indifferently through refinancing at low rates or with a credit guarantees program at rates below the market price (CDS). Still, if banks face liquidity constraints, indirect lending dominates, while if they are capital constrained, credit guarantees that reduce the weight of risky assets in the portfolio, will be more effective.

The fact that the credit market failure underlying suboptimal private provision of credit is the presence of screening costs also points to additional components of effective government intervention in the credit market. Of particular importance are efforts to boost innovation in screening technologies, including the strengthening of public sources of information on the productive sector, both at the individual firm level and regarding the economic perspectives of specific industries or types of firms. To the extent that information and screening technologies have public good characteristics, this is a task in which government intervention has a high potential value. In practice, it is not unusual for governments and multilaterals to support the banking industry in the strengthening of screening technologies. ${ }^{18}$

Our framework also lends itself naturally to comparing developed and emerging markets in terms of both the potential extent of underfinancing and the potential effectiveness of PDB intervention to successfully address this market imperfection. On the former front, our framework captures some of the reasons why underfinancing may be particularly acute in emerging markets, such as underdeveloped financial sectors with poor screening technologies, poor property rights enforcement, and/or low access to effective collateral. On the latter, it warns that countries with weak fiscal capacity

\footnotetext{
${ }^{18}$ For example, the World Bank Group's International Financial Corporation provides advice to financial institutions in assessing the potential of specific types of clients. (See, e.g., IFC's SME Banking Knowledge Guide, 2010, pages 4448 for an example on advice for screening SMEs). In another front, the Colombian public agency for the financing of innovation runs a program that subsidizes selected bank proposals for the development of screening programs for startups (see https://www.innpulsacolombia.com/sites/default/files/convocatoria_bancos_a_creer.pdf)..
} 
may face particularly high distortionary costs of taxation and also be confronted with difficulties in establishing PDBs with a strong enough corporate governance to be able to isolate itself from political pressures and acquire the best banking practices.

One natural question is to what extent our model sheds light on the activities of public financial institutions that provide financing to activities other than productive projects. One particular interesting field is the public financing of real estate. Institutions such as Fannie Mae and Freddy Mac in the United States are also prevalent around the world. While our model ignores distributive considerations, it still shed light on some potential effects of such interventions. In fact, in the context of costly screening of our model, real estate should never be supported by PDBs. This is the case, first, because the loan is likely to be sufficiently collateralized, so that subsidizing credit activity is unnecessary. Second, the marginal screening cost may be zero, as it happens with loans based on credit scoring, so that any subsidy will have no effect on banks incentives to increase the quality of their screening. Consequently, absent considerations regarding redistribution the case for subsidizing residential mortgages is a very weak one. Put differently, the existence of screening costs and imperfect information about buyers is not a plausible reason to argue that private real estate funding is inefficiently low, or that a PDB should provide such funding. Similar arguments have been made by Beck et al (2012) and Sassi and Gasmi (2014). Of course, alternative considerations regarding redistribution could support public mortgages, in which case the optimal design of such policies would need to address those particular considerations.

Assuming costly screening is clearly a natural view of the banking lending process. Still, alternative financial market imperfections might presumably lead to different conclusions regarding the role of PDBs in improving resource allocation. This as a potentially fruitful area for future research.

Although we cover a number of important extensions, much ground is still to be explored even within the scope of a model based on the existence of screening costs. In particular, the political economy of PDBs, elegantly addressed by Hainz and Hakenes(2012) is dismissed in our model by referring to the empirical evidence without modelling the actual trade-offs. While we consider that the second tier intermediated lending by the PDB is free from political interference, the actual analysis may be much richer, as it is possible to sustain an inefficient senile industry by subsidizing both banks and firms for political reasons. Such deviations from efficiency, in turn, lead to the issue 
of PDBs corporate governance, an issue that deserves much deeper research, as it is directly linked to the one of government owned firms (and banks).

The of PDBs in the business and credit cycle also goes beyond the streamlined conclusions that our approach yields. The issue of the PDB's access to funds is also to be addressed, and its ability to provide firms with credit over a longer maturity may have an important impact on the ability of firms to undertake long run investments.

To conclude, we believe it is relevant to explore the justification of PDB activity in the light of what is known about financial markets imperfections. The costly screening approach seems natural and provides a simple framework that allows to draw interesting non trivial conclusions. Clearly, as the field has not been widely researched, we expect future contributions to provide new additional insights in this area.

\section{$7 \quad$ References}

Armendáriz, Beatriz. 1990. "Development Banking." Journal of Development Economics, 58:83-100.

Arping, S., Lóránth, G., \& Morrison, A. D. (2010). "Public initiatives to support entrepreneurs: Credit guarantees versus co-funding." Journal of Financial Stability, 6(1), 26-35.

Arráiz, I., Meléndez, M. \& Stucchi, R. (2014). Partial credit guarantees and firm performance: evidence from Colombia. Small Business Economics, Springer, 43(3), 711-724.

Beck, T., Demirgüç-Kunt, A., and Maksimovic, V., 2005. Financial and Legal Constraints to Firm Growth: Does Firm Size Matter? Journal of Finance 60, 137-177.

Beck, T., Demirgüç-Kunt, A., Laeven, L., and Maksimovic, V., 2006. The Determinants of Financing Obstacles. Journal of International Money and Finance 25, 932-952.

Beck, Thorsten, and Aslı Demirgüç-Kunt. 2006. "Small and MediumSize Enterprises: Access to Finance as a Growth Constraint." Journal of Banking and Finance 30(11):

2931-43.

Beck,Thorsten:Leora F. Klapper and Juan Carlos Mendoza (2008) "The Typology of Partial Credit Guarantee Funds around the World", The World Bank, Policy Research Working Paper 4771. 
Bernanke, Ben S., and Cara S. Lown. "The Credit Crunch,"Brookings Papers on Economic Activity (2:1991), pp. 205-47.

Bolton, P., and X. Freixas. 2000. Equity, bonds, and bank debt: Capital structure and financial market equilibrium under asymmetric information. Journal of Political Economy 108 (2): 324-351.

Broecker, T., 1990, "Credit-worthiness Tests and Interbank Competition," Econometrica, 58, 429-452.

Carbo-Valverde, Santiago, Francisco Rodriguez-Fernandez and Gregory F. Udell (2014), "Trade Credit, the Financial Crisis, and SME Access to Finance," forthcoming, Journal of Money, Credit and Banking.

Carvalho, D. 2014. "The Real Effects of Government-owned Banks." Journal of Finance 69(2).

Cetorelli, Nicola and Pietro Peretto. 2012. "Credit Quantity and Credit Quality: Bank Competition and Capital Accumulation". Journal of Economic Theory, 147(3): 967-998.

Cole, Shawn. 2009. "Fixing Market Failures or Fixing Elections? Agricultural Credit in India." American Economic Journal: Applied Economics: 1: $219-50$.

Diamond, D. W. (1991). "Monitoring and reputation: The choice between bank loans and directly placed debt." Journal of Political Economy 99: 689-721.

Dick, Astrid and Andreas Lehnert (2010) "Personal Bankruptcy and Credit Market Competition" The Journal of Finance, 65(2),655-686

Dinç, S. 2005. "Politicians and Banks: Political Influences in GovernmentOwned Banks in Emerging Countries," Journal of Financial Economics 77: 453-470.

Eslava, Marcela, Arturo Galindo, Marc Hofstetter, and Alejandro Izquierdo (2015) "Scarring Recessions and Credit Constraints: Evidence from Colombian Firm Dynamics," Documento CEDE 2010-27,updated 2015.

Freixas, Xavier; Sjaak Hurkens; Alan Morrison and Nir Vulkan, 2007. "Interbank Competition with Costly Screening," The B.E. Journal of Theoretical Economics, De Gruyter, vol. 7(1), pages 1-27, May.

Gehrig, Thomas and Rune Stenbacka (2011) "Decentralized Screening: Coordination Failure, Multiple Equilibria, and Cycles", Journal of Financial Stability, 7, 2011, 60-69.

Hainz, C., \& Hakenes, H. (2012). The politician and his banker - How to efficiently grant state aid. Journal of Public Economics, 96(1-2), 218-225. 
Hallward-Driemeier, Mary and Bob Rijkers (2013) "Do Crises Catalyze Creative Destruction? Firm-level Evidence from Indonesia," The Review of Economics and Statistics, vol. 95(5), pages 1788-1810.

Haltiwanger, John, Ron Jarmin and Javier Miranda ."Who Creates Jobs? Small Versus Large Versus Young", The Review of Economics and Statistics, Vol. 95, Issue 2 (May 2013) , pp. 347-361

Holmstrom, B., \& Tirole, J. (1997). Financial Intermediation, Loanable Funds, and the Real Sector. The Quarterly Journal of Economics, 112(3), 663-691. Retrieved from http://www.jstor.org/stable/2951252

Honohan, P. (2010). Partial credit guarantees: Principles and practice. Journal of Financial Stability, 6(1), 1-9.

Khwaja, Asim Ijaz, and Atif Mian. 2005. "Do Lenders Favor Politically Connected Firms? Rent Provision in an Emerging Financial Market." Quarterly Journal of Economics 120 (4): 1371-411.

International Financial Corporation (2010) "The SME Banking Knowledge Guide". IF, World Bank Group.

King, Robert G. and Ross Levine "Finance and Growth: Schumpeter Might be Right" The Quarterly Journal of Economics, Vol. 108, No. 3 (Aug., 1993), pp. 717-737

Klapper, Leora, Luc Laeven and Raghuram Rajan. 2006. "Entry Regulation as a Barrier to Entrepreneurship." Journal of Financial Economics 82: 591-62

Levine, Ross and Sara Zervos, (1998), Stock markets, banks, and economic growth. American Economic Review 88: 537-58.

Lazzarini, Sergio G. \& Musacchio, Aldo \& Bandeira-de-Mello, Rodrigo \& Marcon, Rosilene, (2015). "What Do State-Owned Development Banks Do? Evidence from BNDES, 2002-09," World Development, Elsevier, vol. 66(C), pages 237-253.

Luna-Martinez, Jose; Vicente, Carlos Leonardo, (2012). "Global Survey of Development Banks". Policy Research working paper ; no. WPS 5969. Washington, DC: World Bank.

Manove, Michael, A. Jorge Padilla and Marco Pagano"Collateral versus Project Screening: A Model of Lazy Banks" The RAND Journal of Economics Vol. 32, No. 4 (Winter, 2001), pp. 726-744

Rajan, R. G., and L. Zingales. 1998. Financial dependence and growth. American Economic Review 88: 559-586.

Ruckes, M. (2004). Bank Competition and Credit Standards. Review of Financial Studies, 17(4), 1073-1102. 
Salop, S. 1979. Monopolistic competition with outside goods. Bell Journal of Economics 10 (1): 141-156.

Sapienza, P. 2004. "The Effects of Government Ownership on Bank Lending." Journal of Financial Economics 72: 357-384.

Smallridge, Diana and Fernando de Olloqui, (2011) "A Health Diagnostic Tool for Public Development Banks" Inter-American Development Bank, Institutional Capacity and Finance Sector,TECHNICAL NOTES No. IDBTN-225;

The World Bank (2016). "Global Financial Development Report 2015/2016: Long-Term Finance". The World Bank, Washington.

United Nations Dept. of Economic and Social Affairs. 2005. "Rethinking the Role of National PDBs." Revised Background Document for Ad Hoc Expert Group Meeting on "Rethinking the Role of National PDBs." New York. December 1 and 2, 2005 www.un.org/esa/ffd/msc/ndb/NDBsDOCUMENT-REV-E-151106.pdf. 


\subsection{Appendix A: Proof of proposition 1: banks' pricing strategy}

When quoting $R_{i}$, a bank $i$ confronted with $N-1$ competing banks will have an expected revenue equal to:

$$
\Pi\left(R_{i}\right)=\mu q_{i} I\left(p R_{i}-1\right) \prod_{j \neq i}^{N}\left[q_{j}\left(1-F\left(R_{i}\right)\right)+1-q_{j}\right]
$$

Because in a mixed strategy equilibrium all strategies yield the same expected profit, the equality $\Pi\left(R_{i}\right)=K$ allows us to obtain the common cumulative probability distribution $F(R)$, that satisfies $K=\mu q_{i} I\left(p R_{i}-\right.$ 1) $\prod_{j \neq i}^{N}\left[q_{j}\left(1-F\left(R_{i}\right)\right)+1-q_{j}\right]$. The repayment $R_{i}$ is bounded below by the zero profit lower bound, $R_{i} \geq \frac{1}{p}$ and above by the limit $y^{\prime}$, which could correspond to $y-\frac{E}{p}$ in the case where $E$ is the firm's continuation value in the absence of a loan, or pledgeable cash flow $y-\frac{B}{I \Delta p}$ in the moral hazard case of section 4. Because this upper limit is a possible strategy that satisfies $1=F\left(y^{\prime}\right)$ we have:

$$
K=\mu q_{i} I\left(p y^{\prime}-1\right) \prod_{j \neq i}^{N}\left[1-q_{j}\right]
$$

so that, using the assumption of a symmetric equilibrium, expected revenue in the mixed strategy equilibrium can be rewritten as $\mu I q\left(p y^{\prime}-1\right)[1-q]^{N-1}=$ $\mu I q(p R-1)[q(1-F(R))+1-q]^{N-1}$

From which $F(R)$ is obtained

$$
F(R)=\frac{1}{q}\left\{1-(1-q)\left[\frac{p y^{\prime}-1}{p R-1}\right]^{\frac{1}{N-1}}\right\}
$$

Denote by $\underline{R}$ the lower bound for $R_{i}$, which is defined by $F(\underline{R})=0$. Thus, $\underline{R}$ satisfies $1=(1-q)\left[\frac{p y^{\prime}-1}{p \underline{-}-1}\right]^{\frac{1}{N-1}}$ so that

$$
p \underline{R}=1+(1-q)^{N-1}\left(p y^{\prime}-1\right)
$$




\subsection{Appendix B: Proof of proposition 3}

Dropping the dependence of $S_{C}$ and $q_{i}$ on $p$ in the notations, the PDB problem under competition is:

subject to

$$
\max _{S_{C},\left\{q_{i}\right\}} \int_{\underline{p}}^{1}\left\{\mu I\left[p y-1-\lambda S_{C}\right]\left[1-\prod_{i=1}^{N}\left(1-q_{i}\right)\right]-\sum_{i=1}^{N} C\left(q_{i}\right)\right\} f(p) d p
$$

$$
\begin{aligned}
& \mu I\left(p \bar{R}+S_{C}-1\right) \prod_{j \neq i}^{N}\left(1-q_{j}\right)=C^{\prime}\left(q_{i}\right) \text { for each bank } i \\
& S_{C} \geq 0 ;
\end{aligned}
$$

Denote by $\nu_{i}$ the Lagrangian multiplier associated to constraint (??) for bank $i$. The Lagrangian first order conditions for $S_{C}$ and $q_{i}$ become, respectively:

$$
\begin{gathered}
-\lambda\left[1-\prod_{i=1}^{N}\left(1-q_{i}\right)\right] f(p)+\sum_{i=1}^{N} \nu_{i} \prod_{j \neq i}^{N}\left(1-q_{j}\right) \leq 0 \\
{\left[\mu I\left(p y-1-\lambda S_{C}\right) \prod_{j \neq i}^{N}\left(1-q_{j}\right)-C^{\prime}\left(q_{i}\right)\right] f(p)-} \\
-\nu_{i} C^{\prime \prime}\left(q_{i}\right)-\sum_{j \neq i} \nu_{j}\left(p \bar{R}+S_{C}-1\right) \mu I \prod_{k \neq j, k \neq i}^{N}\left(1-q_{k}\right)=0 \text { for every } i
\end{gathered}
$$

In a symmetric equilibrium $q_{i}=q$ and $\nu_{i}=\nu$, imply

$$
\left[\mu I(1-q)^{N-1}\left(p y-1-\lambda S_{C}\right)-C^{\prime}(q)\right] f(p)-\nu C^{\prime \prime}(q)-(N-1) \nu \mu I(p \bar{R}+
$$
$\left.S_{C}-1\right)(1-q)^{N-2}=0$

Substracting (20) from the previous equation leads to

$$
\mu I(1-q)^{N-1}\left[\left(p(y-\bar{R})-(1+\lambda) S_{C}\right] f(p)-\nu C^{\prime \prime}(q)-\nu(N-1)(1-q)^{N-2} \mu I\left(p \bar{R}+S_{C}-1\right)=0\right.
$$

For $S_{C}>0$ we obtain $\nu=\frac{\lambda\left(1-(1-q)^{N}\right) f(p)}{N(1-q)^{N-1}}$. Replacing yields

$$
\begin{array}{r}
(1-q)^{N-1}\left[\left(p(y-\bar{R})-(1+\lambda) S_{C}\right]-\frac{\lambda\left(1-(1-q)^{N}\right)}{\mu I N(1-q)^{N-1}} C^{\prime \prime}(q)\right. \\
-\frac{(N-1) \lambda\left(1-(1-q)^{N}\right)}{N(1-q)}\left(p \bar{R}+S_{C}-1\right)=0
\end{array}
$$


or, equivalently:

$$
\begin{aligned}
& (1-q)^{N-1}\left(p(y-\bar{R})-\frac{\lambda\left(1-(1-q)^{N}\right)}{\mu I N(1-q)^{N-1}} C^{\prime \prime}(q)-\frac{(N-1) \lambda\left(1-(1-q)^{N}\right)}{N(1-q)}(p \bar{R}-1)\right. \\
= & (1-q)^{N-1}\left(1+\lambda+\frac{(N-1) \lambda\left(1-(1-q)^{N}\right)}{N(1-q)^{N}}\right) S_{C}
\end{aligned}
$$

So that the optimal subsidy satisfies

$$
\begin{aligned}
S_{C}= & \frac{1}{1+\lambda+\frac{(N-1) \lambda\left(1-(1-q)^{N}\right)}{N(1-q)^{N}}} * \\
& \left\{p(y-\bar{R})-\lambda \frac{\left(1-(1-q)^{N}\right)}{\mu I N(1-q)^{2 N-2}} C^{\prime \prime}(q)-\frac{(N-1) \lambda\left(1-(1-q)^{N}\right)}{N(1-q)^{N}}(p \bar{R}-1)\right\}
\end{aligned}
$$

\subsection{Appendix C: Second best in the case of limited collateral}

Denote by $\Gamma_{1} \equiv(p y-1) \frac{V}{\nu_{B}}-(1-p) \delta V$ and $\Gamma_{2}=\frac{\left[\left(p R_{V}+(1-p) \nu_{B}\right)-1\right] V}{N \nu_{B}}$ The second best problem is stated as

$$
\begin{aligned}
& \max _{S_{C}, q} \int_{\underline{p}}^{1} \mu\left\{\left[1-\prod_{i=1}^{N}\left(1-q_{i}\right)\right]\left(p y-1-\lambda S_{C}\right) I+\prod_{i=1}^{N}\left(1-q_{i}\right) \Gamma_{1}-\sum_{i=1}^{N} C\left(q_{i}\right)\right\} f(p) d p \\
& \left.\prod_{\substack{j=1, j \neq i \\
S_{C} \geq 0 ;}}^{N}\left(1-q_{j}\right) \mu\left\{\left(p \bar{R}+S_{C}-1\right) I-\Gamma_{2}\right\}-C^{\prime}\left(q_{i}\right)\right)=0 \quad i=1, \ldots N \\
& \quad 1 \geq q_{i} \geq 0 ;
\end{aligned}
$$

Denote, as before, by $\nu_{i}$ the Lagrangian multiplier associated to the first constraint.

The first order conditions with respect to $S_{C}$ and $q$ are: 


$$
\begin{gathered}
-\lambda\left[1-\prod_{i=1}^{N}\left(1-q_{i}\right)\right] f(p)+\sum_{i=1}^{N} \nu_{i} \prod_{j \neq i}^{N}\left(1-q_{j}\right) \leq 0 \\
\mu \prod_{j=1, j \neq i}^{N}\left(1-q_{j}\right)\left\{\left(p y-1-\lambda S_{C}(p)\right) I-\Gamma_{1}\right\}- \\
-C^{\prime}\left(q_{i}\right)-\frac{\nu(p) C^{\prime \prime}\left(q_{i}\right)}{f(p)}-\sum_{j \neq i} \nu_{j} \mu \prod_{k \neq j, k \neq i}^{N}\left(1-q_{k}\right)\left(\left(p \bar{R}+S_{C}-1\right) I-\Gamma_{2}\right)=0
\end{gathered}
$$

In a symmetric equilibrium $q_{i}=q$ and $\nu_{i}=\nu$, substracting the above conditions read as follows.

$$
\begin{gathered}
-\lambda\left[1-(1-q)^{N}\right] f(p)+\sum_{i=1}^{N} \nu_{i}(1-q)^{N-1} \leq 0 \\
\mu(1-q)^{N-1}\left\{\left(p y-1-\lambda S_{C}(p)\right) I-\Gamma_{1}\right\}- \\
-C^{\prime}(q)-\frac{\nu C^{\prime \prime}(q)}{f(p)}-(N-1) \frac{\nu}{f(p)} \mu(1-q)^{N-2}\left(\left(p \bar{R}+S_{C}-1\right) I-\Gamma_{2}\right)=0
\end{gathered}
$$

while optimal bank behavior is characterized by

$$
\left.\mu(1-q)^{N-1}\left\{\left(p \bar{R}+S_{C}-1\right) I-\Gamma_{2}\right\}-C^{\prime}(q)\right)=0
$$

Substracting from (22a) yields:

$$
\begin{gathered}
\mu(1-q)^{N-1}\left\{\left(p(y-\bar{R})-(1+\lambda) S_{C}\right) I-\Gamma_{1}+\Gamma_{2}\right\}-\frac{\nu C^{\prime \prime}\left(q_{i}\right)}{f(p)} \\
-(N-1) \frac{\nu}{f(p)} \mu(1-q)^{N-2}\left(\left(p \bar{R}+S_{C}-1\right) I-\Gamma_{2}\right)=0
\end{gathered}
$$

For $S_{C}>0$ we obtain $\nu=\frac{\lambda\left(1-(1-q)^{N}\right) f(p)}{N(1-q)^{N-1}}$. Replacing yields

$$
\begin{aligned}
(1-q)^{N-1}\left[\left(p(y-\bar{R})-(1+\lambda) S_{C}\right) I-\Gamma_{1}+\Gamma_{2}\right]-\frac{\lambda\left(1-(1-q)^{N}\right)}{N(1-q)^{N-1}} C^{\prime \prime}(q)- & \\
-\frac{(N-1) \lambda\left(1-(1-q)^{N}\right)}{N(1-q)}\left(\left(p \bar{R}+S_{C}-1\right) I-\Gamma_{2}\right) & =0
\end{aligned}
$$


or, equivalently:

$$
\begin{gathered}
(1-q)^{N-1}\left[\left(p(y-\bar{R}) I-\Gamma_{1}+\Gamma_{2}\right]-\frac{\lambda\left(1-(1-q)^{N}\right)}{N(1-q)^{N-1}} C^{\prime \prime}(q)\right. \\
-\frac{(N-1) \lambda\left(1-(1-q)^{N}\right)}{N(1-q)}\left((p \bar{R}-1) I-\Gamma_{2}\right)= \\
=(1-q)^{N-1}\left(1+\lambda+\frac{(N-1) \lambda\left(1-(1-q)^{N}\right)}{N(1-q)^{N}}\right) S_{C} \quad I
\end{gathered}
$$

So that the optimal subsidy satisfies

$$
\begin{array}{r}
S_{C}=\frac{1}{\left(1+\lambda+\frac{(N-1) \lambda\left(1-(1-q)^{N}\right)}{N(1-q)^{N}}\right) I} \\
\left\{\left[\left(p(y-\bar{R}) I-\Gamma_{1}+\Gamma_{2}\right]-\lambda \frac{\left(1-(1-q)^{N}\right)}{\mu N(1-q)^{2 N-2}} C^{\prime \prime}(q)\right.\right. \\
\left.-\frac{(N-1) \lambda\left(1-(1-q)^{N}\right)}{N(1-q)^{N}}\left((p \bar{R}-1) I-\Gamma_{2}\right)\right\}
\end{array}
$$

